\title{
Integration of Information, Linguistic and Artistic Milieux of Education in the System of General Education with the Use of Music Computer Technologies
}

\author{
Irina B. Gorbunova, Irina O. Tovpich and Olga S. Yakimchuk
}

\begin{abstract}
The article highlights the pedagogical experience of the process of integration of information, linguistic and artistic means of education in the system of general education on the example of secondary school with in-depth study of subjects of the musical cycle and English; the process of implementation of integration of information and artistic means of education in the system of general education with the use of contemporary music computer technologies as one of the tools in the formation of information educational environment of the school aimed at achieving new educational results by all participants of the educational process is illustrated; metatechnology of formation of values of through (continuous) education by means of modern creative digital educational environment is presented.
\end{abstract}

Keywords- general education, information educational environment, interactive educational technologies, music computer technologies.

\section{INTRODUCTION}

Training of educated and intellectually developed generation as the most important condition for sustainable development and modernization of the society is a priority task of contemporary education, the question of methodological and methodological support of this process naturally arises. For example, the popularization of scientific knowledge and ideas in the scientific and entertainment museum centers, giving an opportunity to participate in experiments, experiments and other cognitive activities, have become one of the trends of the contemporary museum-pedagogical process, and the creation of large-scale children's technology parks, allowing children to conduct independent research activities, created the preconditions for the introduction of a new standard of additional education in large cities and regions.

However, the school remains the place where the child spends most of the school day and receives additional education. In some cases, this hinders the possibility of development due to the weak technological equipment and (or)

Irina B. Gorbunova. She is now with the Department of Information Technology, Institute of Computer Science and Technological Education of the Herzen State Pedagogical University of Russia and Educational and Methodological Laboratory Music Computer Technologies of the Herzen State Pedagogical University of Russia, St. Petersburg.

Olga S. Yakimchuk, Associate Professor, The Herzen State Pedagogical University of Russia, St. Petersburg, Russia

Irina O. Tovpich, The Herzen State Pedagogical University of Russia, St. Petersburg, Russia the lack of appropriate methodological developments, visual tutorial, maquettes, models and other materials that expand the information educational space. As a result, school education is in dire need of opportunities to conduct both scientific and educational, and project activities at a level close to such centers, but, if possible, on their own and without attracting large-scale funding.

\section{ADDITIVE EDUCATIONAL TECHNOLOGIES}

With the advent and mass availability of additive technologies, the Internet and free software, it becomes possible to create a digital educational environment that integrates knowledge, methodological and other developments in this area. They are created in an easily replicated format that allows each educational institution, each child or adult to take advantage of the ready development of didactic educational or other developmental materials based on additive technologies, as well as to offer their own development created in a high-tech digital educational environment. The idea of such developments is not new and was present in the Russian scientific and technical periodicals in the form of "do it for school" sections, working as an excellent motivational tool for future researchers. Development of additive technologies and licensing is Open Source spawned similar projects in the foreign language segments of the Internet (for example, www.thingiverse.com, myminifactory.com), but they are focused not only on educational objectives, and community people dedicated to the additive technologies, and as a result do not have the methodological developments in the use of the proposed projects there in training activities. The proposed project integrates specific pedagogical experience and contributes to the creation of a high-tech creative educational environment that allows teachers and pupils to share not only technical developments, but also ways to use them in educational institutions.

\section{SYNTHESIS OF GENERAL AND ADDITIONAL EDUCATION OF PUPILS AT SECONDARY SCHOOLS}

The introduction of a new effective model of synthesis of general and additional education of children by one educational institution, available for replication in various educational institutions and provides a joint effort of teaching staff, parents and pupils to form a system of accelerated development of children's technical and creative abilities (often - in their relationship) allows training future engineers, scientists, 
representatives of creative professions. Pupils' motivation to receive high-tech and engineering professions is a possibility to develop creative abilities and realize the values of continuous education. The active inclusion in this process of music computer technologies (MCT), digital arts and the possibilities of modern digital creative educational environment will also allow forming a new type of specialists capable of active creative activity within the conditions of functioning of network infrastructure and digital technologies [1]-[3].

Among the main objectives of our project, which allows implementing of the synthesis of general and additional education of pupils in one educational institution, we highlight the following:

1) to teach the pupil to identify and obtain the necessary information (development metatechnology-learning) in modern digital educational environment;

2) to teach the skills of self-motivation, self-regulation and self-understanding (practical development of psychotechnologies-application of "instructions to the human body");

3) to teach an effective communication (teamwork) and effective problem solving (metatechnological art - technology of inventive problem solving, in Russian “TRIZ”).

Pupils' skills:

- self-motivation,

- ability to learn (self-learning),

- self-regulation,

- self-understanding,

- inventiveness,

- ability to work in a team.

\section{PROJECT DESCRIPTION "MAKE-4-SCHOOL»}

Digital educational space "MAKE-4-SCHOOL" is:

- environment for accelerated development of technical and creative abilities of children;

- space for creative and methodical interaction;

- stimulus for the formation of inventive thinking;

- advanced technologies of development of the child's personal orientations;

- a new educational format for children in the field of engineering, based on the integration model of the dissemination of technological knowledge, creative design and team activities.

The project consists of two complementary parts, involving joint the development for over several years and the translation of experience to other educational organizations.

Part one. Innovative laboratory

The forces of pupils of School no. 8 "Music" in the framework of extracurricular activities have already assembled a 3D printer project Prusa3, repeatedly upgraded and is they are working on at the creation of large-format 3D printer of their own design based on printed parts using the concept of RepRap. The devices are abundantly used in the course of "Music Computer Technologies" for prototyping musical instruments of original designs, wind instruments mouthpieces and other elements used in the educational process. One or even two 3D printing devices for the development of 3D models on the scale of the planned projects is not enough. Currently, free software OpenScad and Blender are being used for their implementation, which works well on low-power computers, but it hinders the development of pupils' engineering and design skills; educational versions of professional software, the corresponding hardware and additional software are installed.

Part two. Methodical website development MAKE-4-SCHOOL.RU

A digital educational environment is being created and it describes the activities of the innovation laboratory and methodological developments that arise both in the process of pupils' joint work and in the framework of free exchange on the Internet, the implementation of joint projects with foreign partners and the methodological segment that allows broadcasting the experience of successful projects not only of School no. 8 "Music", but also of other participants in the educational process.

For example, it is proposed to implement a pedagogically new approach to teaching children musical literacy, focused on the modern child, brought up largely under the influence of computer logics and aesthetics. In particular, the inclusion of MIDI-keyboard in music lessons in secondary school allows you to provide maximum opportunities for each pupil's creative activity, regardless of his musical abilities [4]-[8]. The difference is that the study of computer science in a school with in-depth study of musical disciplines can be built on materials related to music. Thus, in practice, we implement meta-methodical technology (meta-methodical approach) and inter-subject integration: musical computer (MC) creates the necessary framework for effective music lessons using $\mathrm{MC}$ [9]-[10] as a learning tool at the lesson.

\section{USING THE MUSIC COMPUTER TECHNOLOGIES IN THE PROJECT}

Active inclusion of MCT in the educational process allows achieving the following learning goals:

- obtaining new sustainable educational results taking into account the specifics of the changing society and its modern needs;

- creation of an integrated digital learning environment;

- formation of pupils' activity research approach to understanding of knowledge;

- mastering the ability to use computer technology as a practical tool for working with the use of MCT;

- formation of pupils' ability of independent formulation and finding a solution to creative problems, critical attitude to existing information and intellectual involvement in the desired problem;

- education of pupils with active position to knowledge.

The use of MCT in the activities of a contemporary teacher-musician involves the following tasks:

- to include in the system of schoolchildren's music education modern technologies of sound reproduction; 
- to significantly expand the set of information and illustrative materials available for pupils and teachers in the classroom and outside the classroom [11]-[12];

- to improve the quality of the material presentation and make it more interesting and attractive to pupils compared with traditional textbooks;

- to support the creative and research work of pupils and teachers, etc.

Computer musical creativity is a means of formation of information competence of both the pupil and the contemporary teacher-musician [13]-[15].

In addition to solving these priorities, the use of MCT and electronic musical instruments allows the application of computer services that greatly facilitate the work of the teacher and the pupil: a quick search for information, the preservation of intermediate results and its results, automatic verification of test tasks, etc. Based on the best examples of classical music, with the help of a set of programs developed by us, the introduction of MCT into the educational process corresponds to the contemporary level of education [16]-[19].

\section{CONCLUSION}

The article presents the experience of implementation of the integration process of information, linguistic and artistic means of education in the system of general education on the example of secondary school with in-depth study of music cycle and English allows you to create a model of synthesis of children's general and additional education by one educational institution, available for replication in various educational institutions.

The process of integration of information and artistic means of education in the system of general education with the use of contemporary music computer technologies as one of the tools in the formation of high-tech educational creative environment of the school, aimed at achieving new educational results by all participants of the educational process is illustrated.

Metatechnology of the formation of values through (continuous) education using the tools of digital creative educational environment (media) is set out.

\section{REFERENCES}

[1] Gorbunova, I.B. (2015). Computer Science and Computer Music Technologies in Education. Theory and Practice of Social Development, $12,428-432$.

[2] Gorbunova, I.B. (2017). Information Technology in Music and Music Education. The World of Science, Culture, Education, 2(63), 206-210

[3] Gorbunova, I.B. (2017). Music Computer: Modeling the Process of Musical Creativity. The World of Science, Culture, Education, 4(65), 145-148.

[4] Gorbunova, I.B. "Music Computer Technologies and Digital Humanities". In Prof. Dr. I.B. Gorbunova (Ed.), Contemporary Musical Education - 2015. St. Petersburg, Russia. Proceedings of the annual 14th International Research and Practical Conference, pp. 29-34, Dec. 2015.

[5] Gorbunova, I.B. (2012). Musical-Computer Technology: the Laboratory. Mediamusic, $1 . \quad$ Retrieved from: http://mediamusic-journal.com/Issues/1_5.html

[6] Gorbunova, I.B. "New Tool for a Musician". In Prof. Dr. B. Topcuoglu, Prof. Dr. M. Plaisent, Dr. Thaweesak Yingthawornsuk (Ed), 15th Int'l Conference on Education, Economics, Humanities and Interdisciplinary Studies. Paris, France. EEHIS-18 International Conference Proceedings, pp. 107-113, June 2018. DOI: https://doi.org/10.17758/URUAE2.AE06184024

[7] Gorbunova, I.B. "Electronic Musical Instruments: to the Problem of Formation of Performance Mastery". In Prof. Dr. Rahim Ahmadi, Prof. Kazuaki Maeda, Prof. Dr. M. Plaisent (Ed.), 16th International Conference on Literature, Languages, Humanities \& Social Sciences (LLHSS-18). Budapest, Hungary. Int'l Conference Proceedings, pp. 23-29, Oct. 2018. DOI: https://doi.org/10.17758/ URUAE4.UH10184023

[8] Gorbunova, I.B. and Chibirev, S.V. "Music Computer Technologies and the Problem of Modeling the Process of Musical Creativity", Regional Informatics "RI-2014". St. Petersburg, Russia. Proceedings of the XIV St. Petersburg International Conference, pp. 293-295, Oct. 2014.

[9] Gorbunova, I. B. and Davletova, K. B. "Studying Electronic Musical Instruments: Main Content of the Musical Informatics Training Course for Children". In (Ed.), International Conference on Education and Social Science (ICESS-2018). London, UK. ISERD International Conference Proceedings, pp. 24 - 27, Sept. 2018.

[10] Gorbunova, I., \& Govorova. A. (2018) Music Computer Technologies in Informatics and Music Studies at Schools for Children with Deep Visual Impairments: From the Experience. In: Pozdniakov S., Dagienè V. (eds) Informatics in Schools. Fundamentals of Computer Science and Software Engineering. ISSEP 2018. Lecture Notes in Computer Science, vol 11169. Springer, Cham DOI: https://doi.org/10.1007/978-3-030-02750-6_29

[11] Gorbunova I.B., Hiner E. (2018). Music Education Today: Music Computer Technology System for Learning Music Soft Way to Mozart. The World of Science, Culture, Education, no. 5 (72), pp. 336-341.

[12] Gorbunova, I.B., Zalivadny, M.S. The Integrative Model for the Semantic Space of Music: Perspectives of Unifying Musicology and Musical Education. Music Scholarship. 2018. No. 3, pp. 55-64. DOI: http://dx.doi.org/10.17674/1997-0854.2018.4.055-064

[13] Gorbunova, I.B., Zalivadny, M.S. and Tovpich, I.O. "Mathematical Methods of Research in Musicology: an Attempt of Analyzing a Material from Contemporary Historical Heritage (Reflections on Xenakis' Book MUSIQUES FORMELLES)". In Prof. Dr. B. Topcuoglu, Prof. Dr. M. Plaisent, Dr. Thaweesak Yingthawornsuk (Ed), 15th Int'l Conference on Education, Economics, Humanities and Interdisciplinary Studies. Paris, France. EEHIS-18 International Conference Proceedings, pp. 97-102, June 2018. DOI: https://doi.org/10.17758/URUAE2.AE06184022

[14] Gorbunova, I.B. and Plotnikov, K.Yu. "The Position of Music Computer Technologies in Informatics Course for Secondary School", International Conference on Multidisciplinary Research \& Practice (ICMRP). Oxford, UK. Proceedings of the ICMRP International Conference, pp. 1- 4, Sept. 2018.

[15] Gorbunova, I.B. and Voronov, A.M. "Music Computer Technologies in Computer Science and Music Studies at Schools for Children with Deep Visual Impairment”. In Prof. Dr. Rahim Ahmadi, Prof. Kazuaki Maeda, Prof. Dr. M. Plaisent (Ed.), 16th International Conference on Literature, Languages, Humanities \& Social Sciences (LLHSS-18). Budapest, Hungary. Int'l Conference Proceedings, pp. 15-19, Oct. 2018. DOI: https://doi.org/10.17758/ URUAE4.UH10184021

[16] Gorbunova, I. B. \& Hiner, H. Interactive Network Technologies Music Learning: the Program 'Soft Way to Mozart'. Bulletin of Orel State University. Series: New Humanitarian Studies, 4 (39), 104-109, 2014.

[17] I.B. Gorbunova, and H. Hinner, "Music Computer Technologies and Interactive Network Systems of Learning Music", International Conference on Psychology, Language and Teaching (ICPLT). Oxford, UK. Proceedings of the IIER International Conference, pp. 16-21, Sept. 2018.

[18] I. Gorbunova, and K. Plotnikov, "Music Computer Technologies in Informatics Course for Secondary School", Regional Informatics "RI-2018". St. Petersburg, Russia. Proceedings of the St. Petersburg International Conference, pp. 370-372, Oct. 2018.

[19] Gorbunova, I.B., Davletova, K.B. (2018). Musical Informatics: on the Contents of a Training Course for Classes of Electronic Musical Instrument. The World of Science, Culture, Education, no. 5 (72), pp. 329-331. 


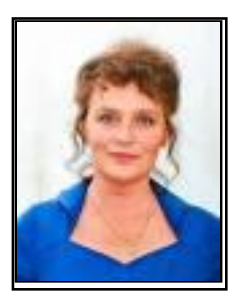

Irina B. Gorbunova was born in Saint Petersburg (Leningrad). DipMus, Special Music Higher School of the St. Petersburg State Conservatory named after N.A. Rimsky-Korsakov; BSc in Computer Science: Information Technology, Computer Science and Multimedia, Leningrad State University, Ussurisk State Pedagogical University; MA in Education, the Herzen State Pedagogical University of Russia; PhD in Information Technology and Pedagogic Sciences, the Herzen State Pedagogical University of Russia, St. Petersburg, 1989; Doctor degree: Doctor of Pedagogic Sciences and Information Technology, the Herzen State Pedagogical University of Russia, St. Petersburg, 1999. Dr. Gorbunova, Full Professor, PhD in Sc., Doctor of Pedagogic Sciences, Chief Researcher of the Educational and Methodological Laboratory Music Computer Technologies of the Herzen State Pedagogical University of Russia, St. Petersburg.

She was on a number of business trips abroad, among them working trip to the USA (1999); lecturing and giving research and practice seminars in Hungury $(2003,2005,2017)$; business trip to the UK (2016); she was a member of the Jury of national and international competitions of musical creativity, including Bridge of Friendship (Dortmund, Germany, 2011), etc. Work experience; 1990 - 2010 - Associate Professor, Professor of the Department of Information Technology of the Herzen State Pedagogical University of Russia, St. Petersburg; 2010 - present - Full Professor of the Department of Information Technology, Institute of Computer Science and Technological Education of the Herzen State Pedagogical University of Russia, St. Petersburg; 2002 - present - Chief Researcher of the Educational and Methodological Laboratory Music Computer Technologies of the Herzen State Pedagogical University of Russia, St. Petersburg. She has more than 300 scientific publications, among them are monographs Music Computer Technologies: Historical-Theoretical and Practical Aspects, St. Petersburg: Publ. house "SMIO Press" (2007, 560 pp.) and Music Computer Technologies: The Problem of Modeling the Process of Musical Creativity, compiled with participation of S. V. Chibirev, St. Petersburg: Publ. house of the Herzen State Pedagogical University of Russia (2012, 160 pp.); course book Information Technology in Music, vol. 1 - 4: vol. 1, Architectonics of musical sound (2009, 175 pp.), vol. 2, Musical Synthesizers (2010, 205 pp.), vol. 3, Music Computer (2011, 411 pp.), Music, Mathematics and Computer Science, vol. 4, compiled with participation of Mikhail S. Zalivadny (2013, 181 pp.), St. Petersburg: Publ. house of the Herzen State Pedagogical University of Russia. Her research activities include such directions as: MCT in professional music education (as a means to expand creative opportunities); MCT in general musical education (as one of the means of education); MCT as a means of rehabilitation of people with disabilities; MCT as the new direction in preparation of specialists of humanitarian and technological profile; MCT in the field of digital arts; MCT in information technology, psychoacoustics and musical acoustics; system of training arrangements and the art of performing skills on electronic musical instruments. Her circle of interests also includes the problems of interrelation of natural and technical sciences and humanities, as well as the possibilities of applying the results of such interrelation for the purposes of music education and upbringing. She also takes part in working out the specialized software for computer music devices and in application of this software in pedagogical processes. Her developments and researches also belong to the field of musical pedagogics and musicology, musical Informatics, computer modeling of processes of musical creativity, timbre programming, art of performing skills and arrangement on electronic musical instruments, creative work in the field of computer music, mathematical methods in musicology.

Prof. Dr. Gorbunova is Chairman of the Organizing Committee of the international research and practice conference Contemporary Music Education, Chairman of the Organizing Committee of the international research and practical conference Music Computer Technologies in the System of Contemporary Education. Dr. Gorbunova is a member of the Jury of national and international competitions of musical creative works, including Electronic Palette (Saint-Petersburg), Music and Electronics (Moscow), Music of the XXI Century (Moscow / Saint-Petersburg), International Festivals and Competitions Musical Electronics and Multimedia (Moscow / Saint-Petersburg), Clarine of the XXI Century (Saint-Petersburg), The World of Art without Borders (Saint-Petersburg, Russia - Szeged, Hungary), Bridge of Friendship (Dortmund, Germany), All-Russian Competition of Electroacoustic Music DEMO
(Saint-Petersburg). She is a member of Editorial Boards of International Journals: Music Scholarship / Problemy Muzykal'noj Nauki (SCOPUS), The World of Science, Culture, Education / Mir Nauki, Kul'tury, Obrazovaniya, Electronic international scientific journal of music and sound in electronic mass media, film, Internet, and multimedia MEDIAMUSIC. Prof. Dr. Gorbunova has developed first ever course in Music, called Music Computer Technologies, which has been offered under the Bachelors of Arts and Sciences (BASc), , which in 2004 carried out student recruitment in different regions and educational institutions of Russia and she also leads post-graduate courses "Music Computer Technologies in Education" available under the MA in Music Education, since 2006. Prof. Dr. Gorbunova supervises a number of doctoral and post-doctoral students (more than 30) and lectures on Music Computer Technologies and Information Technology in Music. She supervises research in various directions, among them there are: Theory and history of culture, Music Art, Information system and processes, Theory and methodology of professional education, Mathematical modelling, numerical methods and program systems, Theory and methods of education and upbringing (in Music, Informatics, natural sciences). The research results of Prof. Gorbunova were published in over 300 refereed publications including 48 books and 255 papers in journals and conference proceedings. Awards and honors: 2003 - Gold medal of the all-Russian Exhibition Centre (former VDNKh); 2005 - Silver medal of the all-Russian Exhibition Centre (former VDNKh); 2009 - Gold medal of the all-Russian Exhibition Centre (former VDNKh); 2009 - Diploma of the winner in the nomination «New educational technologies in ICT environment» of the all-Russian creative contest of scientific-technical solutions, educational products and services in the field of Informatization of the innovative-educational complex «Music computer technologies in the system of modern education»; 2010 - Grand Prix of International Congress-exhibition «Global Education - Education Without Borders»; 2010 - Diploma of the 11th all-Russian forum «Educational environment - 2010» for the project «Digital educational resources «Music computer technologies in education» in nomination of «Creative Competition of scientific developments, innovative solutions and programs in the field of higher vocational education» and many others; 2011 - Laureate of the Prize of the Government «For Outstanding Achievements in the Field of Higher and Secondary Professional Education»; 2013 Honorary Worker of Higher Professional Education of the Russian Federation. 